\title{
Simulation of Early Earth Hydrothermal Chimneys in a Thermal Gradient Environment
}

\author{
Ninos Hermis ${ }^{1}$, Gabriel LeBlanc ${ }^{2}$, Laura M. Barge ${ }^{1}$ \\ ${ }^{1}$ NASA Jet Propulsion Laboratory, California Institute of Technology ${ }^{2}$ The University of Tulsa
}

\section{Corresponding Author}

Ninos Hermis

ninos.y.hermis@jpl.nasa.gov

\section{Citation}

Hermis, N., LeBlanc, G.,

Barge, L.M. Simulation of Early Earth Hydrothermal Chimneys in a Thermal Gradient Environment. J. Vis. Exp. (168), e61789, doi:10.3791/61789 (2021).

\section{Date Published}

February 27, 2021

\section{DOI}

$10.3791 / 61789$

URL

jove.com/video/61789

\section{Abstract}

Deep sea hydrothermal vents are self-organizing precipitates generated from geochemical disequilibria and have been proposed as a possible setting for the emergence of life. The growth of hydrothermal chimneys in a thermal gradient environment within an early Earth vent system was successfully simulated by using different hydrothermal simulants, such as sodium sulfide, which were injected into an early Earth ocean simulant containing dissolved ferrous iron. Moreover, an apparatus was developed to sufficiently cool the ocean simulant to near $0{ }^{\circ} \mathrm{C}$ in a condenser vessel immersed in a cold water bath while injecting a sulfide solution at hot to room temperatures, effectively creating an artificial chimney structure in a temperature gradient environment over a period of a few hours. Such experiments with different chemistries and variable temperature gradients resulted in a variety of morphologies in the chimney structure. The use of ocean and hydrothermal fluid simulants at room temperature resulted in vertical chimneys, whereas the combination of a hot hydrothermal fluid and cold ocean simulant inhibited the formation of robust chimney structures. The customizable 3D printed condenser created for this study acts as a jacketed reaction vessel that can be easily modified and used by different researchers. It will allow the careful control of injection rate and chemical composition of vent and ocean simulants, which should help accurately simulate prebiotic reactions in chimney systems with thermal gradients similar to those of natural systems.

\section{Introduction}

Hydrothermal chimneys are self-organizing chemical garden precipitates generated from geochemical disequilibria within deep-sea vent environments as heated, hydrothermally altered fluid seeps into a colder ocean. In an early Earth scenario, it has been proposed that the chimneys formed at ancient alkaline vents, and that transecting ambient $\mathrm{pH} /$ redox/ chemical gradients could have driven reactions toward the emergence of metabolism ${ }^{1,2,3,4,5,6}$. Hydrothermal vents have also been postulated to exist on other planets including the ocean worlds, Europa and Enceladus ${ }^{7,8,9,10}$. Various 
experiments have been conducted to simulate aspects of proposed prebiotic hydrothermal chimney chemistry including precipitation of catalytic iron sulfide minerals that could reduce $\mathrm{CO}_{2}^{11,12}$, gradient-driven organic synthesis ${ }^{13,14,15}$, and incorporation of organics into chimney structures ${ }^{16}$. In creating experimental setups to mimic hydrothermal vents, whether on Earth or on other worlds, it is essential to consider the geochemical gradients and the open, far-from-equilibrium nature of the system to produce realistic simulations.

In addition to $\mathrm{pH}$, redox, and chemical gradients, hydrothermal vents also impose a thermal gradient across the chimney membrane/wall due to the feed of heated vent fluid into a cold seafloor environment. Cold seafloor ocean temperatures can vary as a function of depth, solar penetration, and salinity; average seafloor ocean depths at vent sites (mostly at mid-ocean ridges) are in the range of $0-4{ }^{\circ} \mathrm{C}^{17}$. Depending on the type of vent, the thermal gradient between ocean and vent fluid can vary dramatically-from the milder gradients of alkaline vents, such as Lost City ${ }^{18,19}$ or the Strytan Hydrothermal Field where the vent fluid is $40-90{ }^{\circ} \mathrm{C}^{20,21}$, to the deep seafloor black smokers where the vent fluid can reach several hundred degrees Celsius $22,23,24,25$. From an origin-of-life perspective, simulation of thermal gradients in hydrothermal systems is significant as they could affect the mineralogy and chemical reactivity of chimney precipitates ${ }^{3,13}$ and/or could affect habitability as hydrothermal chimneys host microbes that take up electrons directly from mineral surfaces ${ }^{26}$. In a gradient across the chimney wall, a range of temperature conditions would be present over a short distance, and the chimney wall would represent a combination of minerals and reactions characteristic of all these thermal regimes.
Laboratory-grown hydrothermal chimneys in thermal gradients were simulated to explore the effects of the cold ocean and hot hydrothermal fluid on this potential prebiotic environment. Generally, because growing simulated hydrothermal chimneys via an injection method with a heated interior and cold exterior presents practical challenges, the most accessible chimney experiments are those done at ambient pressure (therefore not requiring costly and complicated reactors). Previous attempts at lab-grown chimneys in a thermal gradient have not able to produce both a hot/warm hydrothermal fluid and a cold ocean. In an effort to keep the entire chimney at high temperature for long durations to form reactive minerals that can drive organic reactions, some studies heated the whole experiment (ocean and hydrothermal fluid) to $\sim 70{ }^{\circ} \mathrm{C}$ using either a heating jacket or a hot bath ${ }^{13,14}$. Another type of chimney precipitate formation experiment, in a "fuel cell" apparatus, formed the chimney wall simulant on a flat membrane template; these experiments have also been heated in bulk by submerging the fuel cell gradient apparatus in a hot water bath 27,28 . Previous studies have formed simulated hydrothermal chimneys from hot hydrothermal fluids (heated to $\sim 70{ }^{\circ} \mathrm{C}$ using various methods) injected into a room-temperature ocean ${ }^{3,12}$; however, a cold ocean has not been attempted.

This work advances methods for prebiotic chimney growth laboratory simulations ${ }^{4}$ to create a realistic thermal gradient from a cold $\left(0-5{ }^{\circ} \mathrm{C}\right)$ ocean to a heated hydrothermal fluid in which to synthesize chimney materials and test properties of interest. To date, there have been no prebiotic chimney experiments successfully conducted with a realistic temperature gradient for alkaline vents: with the interior vent solution held at $\sim 70{ }^{\circ} \mathrm{C}$ and the exterior ocean solution chilled to $\sim 5{ }^{\circ} \mathrm{C}$. Furthermore, in the few heated chimney experiments that have been conducted, the experimental 
setup is complex and can be costly. Chemical garden experiments have great potential to yield insights about the processes that may have taken place in hydrothermal vents on the early Earth. Hence, the ability to quickly set up multiple variations of a chimney experiment is advantageous, as is the ability to have a simple apparatus that is inexpensive, non-fragile, easily modified, and ideal for students to work with. Presented here is a novel apparatus (Figure 1) designed to facilitate growth of a simulated hydrothermal chimney while maintaining and monitoring a realistic thermal gradient between the cold ocean and heated hydrothermal fluid simulant. This experimental apparatus is similar in design to a jacket reactor, but is a three-dimensional (3D) printed condenser that can be easily produced by any research group interested in conducting similar experiments (see Supplementary printable file). Using this 3D printed condenser, thermal gradient chimney experiments were conducted to test the utility of this apparatus for maintaining robust temperature gradients and to test the effects of temperature gradients on chimney structure and morphology.

\section{Protocol}

\section{Safety considerations}

1. Use laboratory protective equipment for personal protection including nitrile gloves, face goggles, lab coat, and proper shoes (no skin exposed).

1. When using syringes and needles, be careful not to puncture gloves or skin.

2. Check the entire apparatus in the fume hood for leaks.

3. Check the stability of glass vials and condenser on the stand before adding any chemical to the mixture.
2. Operate all thermal gradient experiments in fume to contain water spills.

3. Use all sodium sulfide $\left(\mathrm{Na}_{2} \mathrm{~S} \cdot 9 \mathrm{H}_{2} \mathrm{O}\right)$ in fume as it is hazardous to health.

1. Keep sodium sulfide in the fume hood, and place a balance inside the fume hood for weighing the sulfide amount.

2. Always keep sulfide-containing solutions inside the fume hood as they release toxic $\mathrm{H}_{2} \mathrm{~S}$ gas, and keep sulfide liquid, sharps, and solid waste containers in the fume hood.

3. Do not mix any sulfide solution wastes with other known chemicals.

4. When using reactant $\mathrm{Fe}(\mathrm{II}) \mathrm{Cl}_{2} \bullet 4 \mathrm{H}_{2} \mathrm{O}$, consistently purge with $\mathrm{N}_{2} / \mathrm{Ar}$ as it oxidizes upon exposure to air. Keep solutions anoxic in the fume hood by placing $\mathrm{N}_{2} / \mathrm{Ar}$ gas in the headspace inside the fume hood. Secure with parafilm to prevent further oxidation.

\section{Setup for injection experiments}

1. Clamp the $3 \mathrm{D}$ printed condenser injection on a stand in a fume hood, so that the small port hole is facing the bottom of the fume hood. Make sure the condenser is leveled within the clamp.

2. Create glass "injection vessels" by cutting off $1 \mathrm{~cm}$ from the bottom of a $100 \mathrm{~mL}$ clear glass, crimp-top serum bottle (20 mm crimp seal closure type) using a glass cutter, and make sure that the vessel is open to the air from the bottom up.

1. Clean the vials in a $1 \mathrm{M} \mathrm{HCl}$ acid bath overnight, and then rinse with double-distilled water $\left(\mathrm{ddH}_{2} \mathrm{O}\right)$ before conducting a new experiment. 
2. Re-use glass unless cracked or broken, then dispose.

3. Prepare the injection vials (Figure 1).

1. Collect the following materials: a $20 \mathrm{~mm}$ septum, a $20 \mathrm{~mm}$ aluminum crimp seal, a 0.5-10 $\mu \mathrm{L}$ plastic pipette tip, a $16 \mathrm{G}$ syringe needle, and a crimper tool.

2. Carefully puncture a hole in the center of the rubber septum, and then remove and discard the needle in a sharps waste container.

3. Insert the pipette tip into the needle hole, into the side of the rubber septum that will face inside the crimp top of the vial. Push the pipette tip through the septum so that it pokes out slightly on the other side. NOTE: Do not push all the way through, as this will not give enough clearance to place the crimp seal with the crimper tool.

4. Place the crimper onto the crimp-seal. Squeeze the crimper and seal the septum with the pipette tip onto the injection vessel to make it watertight. After sealing properly, push the pipette tip through the glass jar, so that it protrudes about 1.0" from the glass.

5. Place a clear, flexible, chemical-resistant tube of 1/16" inner diameter on the pipette tip to get a watertight seal on the pipette tip.

NOTE: The tube should be long enough to reach the $16 \mathrm{G}$ syringe on top of the syringe pump as the syringe will pump the hydrothermal fluid through this clear tubing into the ocean simulant.

6. Place the injection vials in the 3D printed condenser in the fume hood, by snaking the tubing through the condenser port hole on the bottom. Make sure that the vial protrudes from the small port hole in the condenser.

NOTE: If multiple condensers are to be used, multiple vials can be set up at once and fed simultaneously by separate syringes.

7. Check for any final leaks by inserting a $10 \mathrm{~mL}$ syringe filled with $\mathrm{ddH}_{2} \mathrm{O}$ and with a $16 \mathrm{G}$ needle into the other end of the open tubing. Carefully insert the 16 $\mathrm{G}$ needle into the tubing so as not to puncture the tube. Slowly inject the $\mathrm{ddH}_{2} \mathrm{O}$ so that it moves up the tubing and into the bottom of the reaction vessel to ensure that the syringe/tube, tube/tip, and crimp seals are all watertight.

8. Secure parafilm tightly over the cut-off top of the vial, and place a small piece of tape onto the top of the parafilm. Punch a small hole through the tape so as the $\mathrm{O}_{2}$ can gas out as $\mathrm{N}_{2} / \mathrm{Ar}$ is pumped in.

9. Set up $\mathrm{N}_{2} / \mathrm{Ar}$ gas lines that will each feed into one of the injection vials from the cut-off top to make the glass vial anoxic before ocean simulant is poured in.

10. Split the gas feed from a $\mathrm{N}_{2} / \mathrm{Ar}$ source into several tubes, so that there is one $\mathrm{N}_{2} / \mathrm{Ar}$ feed for each injection vial (if conducting multiple experiments).

11. Place the syringe (connected to $\mathrm{N}_{2} / \mathrm{Ar}$ ) by puncturing through the tape, hovering over the ocean solution in the vial. Be careful not to penetrate the ocean solution with the needle to avoid disruption of the chimney growth.

\section{Preparation of solutions for chemical garden growth}

1. Preparing the ocean simulant 
1. Prepare $100 \mathrm{~mL}$ of solution for each experiment.

NOTE: In this example, use Table 1 for specific concentrations as the precipitating cations.

2. Create anoxic solutions by first bubbling $100 \mathrm{~mL}$ of dd $_{2} \mathrm{O}$ with $\mathrm{N}_{2} / \mathrm{Ar}$ gas for $\sim 15$ min per $100 \mathrm{~mL}$ in an Erlenmeyer flask.

3. Weigh out and add any of the ocean chemistry ingredients, stirring gently to dissolve (not vigorously so as to not introduce oxygen).

4. After dissolving the reagents, immediately resume light bubbling of the ocean simulant with $\mathrm{N}_{2} / \mathrm{Ar}$ gas while preparing the hydrothermal injections.

2. Preparing hydrothermal fluid simulant (sodium sulfide preparation)

1. Choose one of the injection concentrations shown in Table 1, and prepare $10 \mathrm{~mL}$ of each concentration. Fill $10 \mathrm{~mL}$ syringes with the solutions. Replace the needle caps and set aside.

NOTE: Always keep sulfide-containing solutions and syringes in the fume hood.

2. Weigh the required amount of sodium sulfide $\left(\mathrm{Na}_{2} \mathrm{~S} \cdot 9 \mathrm{H}_{2} \mathrm{O}\right)$ in the fume hood only $(50 \mathrm{~mL}$ of solution with $\mathrm{ddH}_{2} \mathrm{O}$ ).

1. Fill a $50 \mathrm{~mL}$ centrifuge tube with $\mathrm{ddH}_{2} \mathrm{O}$.

2. Place the $\mathrm{Na}_{2} \mathrm{~S} \cdot 9 \mathrm{H}_{2} \mathrm{O}$ in the $50 \mathrm{~mL}$ centrifuge tube, and seal it tightly in the fume hood.

3. Shake the tube thoroughly in the fume hood until all sulfide particles are fully dissolved.

4. Keep the solution anoxic in the fume hood using parafilm into which a $10 \mathrm{G}$ needle injecting $\mathrm{N}_{2} /$ Ar has been inserted.

\section{Setting up the thermistor}

1. Place the thermistor in a stable position on a side bench as close to the fume hood as possible. Insert the USB side of an RS232 adapter cable into the computer USB port.

2. Turn on the power for the thermistor. For directions on setting up cable resistors, see Thermistor procedure in the Supplementary Appendix 2.

3. Turn on the thermistor software on the computer.

1. Scroll down to Communications Port. Select the first few communication ports, and click on the Connect button to the left for each port, until the thermistor connects to the software.

NOTE: The software will show the Reading Configuration bars in green. The sampling icon will keep flashing, showing that it is sampling the current temperature at frequent intervals. If neither of these signals are observed, choose other communication ports. If none of the communication ports work, a pop-up message is seen, stating Communications error or Unable to communicate.

2. If Communications error pops up, close the program and restart. Re-check the ribbon cables, and make sure they are properly connected to the pins on the RS232 cable pinouts.

4. Once connected, make sure Output reads $100 \%$ in red bars.

5. Once the thermistor is flashing frequent interval measurements, change the interval time to $60 \mathrm{~s}$. In the Controller Options box, towards the bottom, clear out 1 $\mathrm{s}$ and change to $60 \mathrm{~s}$. Click on the OK button. 
6. There will be an oval button next to the company logo labeled Auto-scale. Click that button to turn on autoscale. Note the yellow line that will show the temperature readout.

7. Inside the plot area, right-click to adjust the plot to your liking, such as scaling the $\mathrm{x}$ and $\mathrm{y}$ axes.

8. Right click in the plot area, and click on export to Excel before a new reading starts every $5000 \mathrm{~s}$ or $83.33 \mathrm{~min}$ (depending on the recording interval chosen). Save the temperature and time data in the spreadsheet that has been automatically created by the program.

9. Place the metal thermistor probe into the glass ocean vessel within the condenser. Make sure the probe is set off to the side of the glass as the thermistor probe hanging in the middle of the glass vial will interrupt chimney growth. Cover again with parafilm.

\section{Setting up the ice bath}

1. Grab a larger plastic pan and a mid-size bucket. Fill the bucket with water up to half-way.

2. Place the bucket inside the pan, and place ice inside the water until nearly full.

3. Place the two plastic cut-off hoses onto either end of the water pump (Supplementary Appendix 3, Figure 1). Note that the vertical pump opening is where water will be poured in to begin priming, and the horizontal opening is where the water is ejected. Plug in the pump to a power socket, but leave the electric connectors open as they will power the pump when connected.

4. Connect the horizontal plastic hose (Supplementary Appendix 3, Figure 2) to the higher condenser port, facing the right, ensuring that the hose is long enough to reach the ice bucket.
5. Place another cut-off plastic hose to the left (lower) condenser port, ensuring that this hose also is long enough to reach ice water bath. Position this hose over the bucket of ice water into which the water will be ejected from the condenser.

6. Pour cold water through the hose connected to the vertical opening of the pump. When the pump is full of water, reaching all the way to the condenser port, immerse the hose into the ice water bath, and immediately connect the electrical connectors.

NOTE: This may require two people.

7. Prime the pump to start flowing water through condenser, fill the bucket with ice, and place a thermometer in the bucket to check the temperature.

NOTE: Water temperature should reach $\sim 0{ }^{\circ} \mathrm{C}$. See control test in Supplementary Appendix 1 Figure 2.

8. Keep adding more ice to maintain the water at a cold temperature, while removing some of the warmer water.

\section{Prepping for injection}

1. Bring the $\mathrm{dd} \mathrm{H}_{2} \mathrm{O}$ syringes (section 2.3) down next to the hydrothermal fluid injection syringes. Carefully slide the plastic injection tubing off the $\mathrm{dd}_{2} \mathrm{O}$ syringe needle, and immediately transfer it directly onto one of the primary injection syringe needles.

NOTE: Do not puncture the wall of the tubing.

2. Plug in the heater pad to heat the hydrothermal simulant to $70-80^{\circ} \mathrm{C}$. (Warning: higher temperatures can warp or damage the plastic syringe.)

3. Wrap the pad around the sulfide syringe, and firmly screw on two metal clamps around the pad (Supplementary Appendix 3, Figure 3). 
4. Once the clamps are secured in place, place them on the syringe pump, and secure the pump tightly (depends on the syringe pump of choice).

5. Set the temperature on the control box to $\sim 70{ }^{\circ} \mathrm{C}$ by pressing on the up arrow key (Supplementary Appendix 3, Figure 5). Press set/start.

6. Once the heated syringe(s) are locked in place on the syringe pump, set the syringe pump to inject at $1-2 \mathrm{~mL} / \mathrm{h}$.

7. Check that ocean solutions are fully dissolved. If cloudy, stir until mostly dissolved.

8. Titrate the ocean simulant to $\mathrm{pH} 5.5$ to simulate Hadean ocean acidity ${ }^{30,31}$. Use $10 \mathrm{M} \mathrm{HCl}$ and add droplets slowly (under the $\mathrm{N}_{2} / \mathrm{Ar}$ feed) until the $\mathrm{pH}$ meter reads a stable 5.5. If it exceeds 5.5 , use $\mathrm{NaOH}$ to bring the $\mathrm{pH}$ back to more basic levels using the same slow droplet method.

9. Pour one or two ocean solutions in the prefabricated chimney vessels. Pour one ocean solution into the glass vial within the condenser and the other into the roomtemperature vessel with no condenser (if conducting two experiments) (Figure 6).

NOTE: Do not move the temperature probe.

10. Seal the top of the glass vials with parafilm. Replace the $\mathrm{N}_{2} / \mathrm{Ar}$ feed to the top of the headspace of the ocean simulant, taking care not to introduce the needle into the ocean simulant.

11. Program the syringe pump to inject at $1-2 \mathrm{~mL} / \mathrm{h}$ (calibrate for the size of the syringe being used, depending on type of syringe pump), but do not press Start.

12. To prevent thermal loss from occurring through the length of the tubing inject the hot fluid rapidly to make immediate contact with the ocean reservoir. Then, let injection run at
1- $2 \mathrm{ml} / \mathrm{h}$ into the cold ocean. (See thermal test for syringe in Supplementary Appendix 1). Use waste beakers to catch any drips.

13. Start the injection, and start recording the ocean temperature on the thermistor.

\section{Monitoring the temperature and the experiment}

NOTE: Once the water is circulating through the condenser, the thermistor temperature probe will begin to display the fall in temperature within the ocean. The goal is for the temperature to reach near $0{ }^{\circ} \mathrm{C}$. See Table 2 for the precise temperature (thermal) gradient settings.

1. Save all temperature data by right-clicking on the plot area, and save as a .CSV file.

NOTE: The program will record up to $5000 \mathrm{~s}$ worth of temperature data and then start over.

2. Keep adding ice into the bucket to maintain near-freezing temperatures, until the chimney has mostly developed, or at least until the syringe is nearly empty.

3. Monitor the room-temperature chimney as well. Take frequent photographs throughout chimney growth for both chimneys.

4. Once the chimney is complete, place a small ruler next to both chimneys, and then take and save images.

NOTE: The entire process should run for $\sim 6 \mathrm{~h}$.

\section{Ending the experiment}

1. Stop the syringe pump, then stop recording the temperature on the thermistor, and save the data in a spreadsheet.

2. Turn off the $\mathrm{N}_{2} / \mathrm{Ar}$ flow, and remove the lines and the parafilm from the injection vessels. 
3. If needed, sample the ocean solution or precipitate for further analysis. To carefully remove the reservoir solution without disturbing the precipitate, use a $25 \mathrm{~mL}$ pipette to carefully pipette off several aliquots of the reservoir solution, and discard the solution in a waste beaker.

4. Carefully drain the vial within the condenser into a waste beaker. Remove the tubing from the syringe, and let the ocean solution drain into the beaker in the fume hood. Do the same for the vial with no condenser.

5. Remove the vessels, one at a time, from the clamp, and use $d_{d H_{2}} \mathrm{O}$ to rinse out the pieces of precipitate into a waste beaker.

6. Remove the tubing and the syringes from the syringe pump. Empty the syringes and any extra injection fluid into the waste transfer beaker, and dispose of the syringes in a sulfide sharps container kept in the fume hood.

7. Remove the tubing from the experiment vial and dispose of it in a solid waste bag. Uncrimp the seal and dispose of the septum, seal, and pipette tip.

8. Rinse out the glass experiment vial, and soak it overnight in a $1 \mathrm{M} \mathrm{HCl}$ acid bath.

NOTE: Glassware that has been in contact with sodium sulfide will release toxic $\mathrm{H}_{2} \mathrm{~S}$ gas when placed in acid. Hence, keep all acid baths inside the fume hood.

\section{Representative Results}

As in previous studies ${ }^{1,2,13,29}$; once the hydrothermal fluid simulant reached the ocean vial, a mineral precipitate structure began to form that grew thicker and taller for the duration of the injection. The iron sulfide chimneys were delicate structures that were not very robust and were easily disaggregated if the ocean vial or injection was physically disturbed. This is consistent with results from previous studies $^{3}$. The chemical concentration of the sulfide solution also played a vital role in the morphology of the sulfide chimneys. More concentrated solutions of sulfide allowed for taller and sturdy mineral precipitates, as shown in Figure 5, whereas lower concentrations of sulfide solutions produced weak chimney structures. In some cases, no structure was formed, only a liquid sulfide-mineral "soup" was created, that would eventually settle out as a sediment (Figure 3D). This occurred in both thermal and non-thermal gradient conditions.

In thermal gradient chimney experiments with iron sulfide, solid chimney structures generally did not coalesce as well as they did at room temperature. Figure $3 \mathrm{E}-\mathrm{H}$ shows the morphology of an iron sulfide chimney grown between a cold ocean and room-temperature hydrothermal fluid. The chimneys in the temperature gradient were string-like and tenuous in nature, whereas non-thermal gradient results (Figure 3A-D) show more semi-permanent structures. The same was true when the hydrothermal fluid was heated (Figure 4). The exception was at higher sulfide and iron concentrations (Figure 5) where a solid iron sulfide chimney was formed between a room-temperature hydrothermal solution and cold ocean simulant. 
The effect of a thermal gradient on the growth of iron hydroxide chimneys was also tested. The results showed patterns that were similar to those of the iron sulfide chimney: while the room-temperature iron hydroxide experiment resulted in a more robust chimney precipitate, the thermal gradient experiment between the warm hydrothermal fluid and the cold ocean resulted in a smaller mound of chimney material that did not coalesce vertically (Figure 6). In contrast to the tall upright structures of iron hydroxide chimneys observed in previous work (in room-temperature experiments) $)^{29}$, our thermal gradient experiment showed a different morphology.

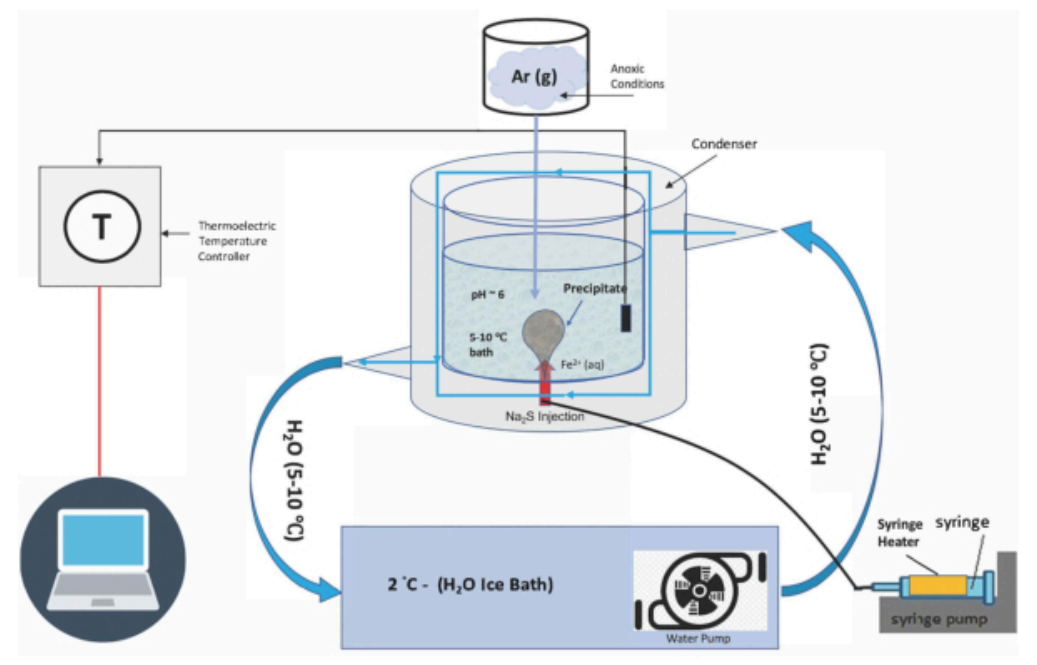

Figure 1: Thermal gradient chimney apparatus. Please click here to view a larger version of this figure. 

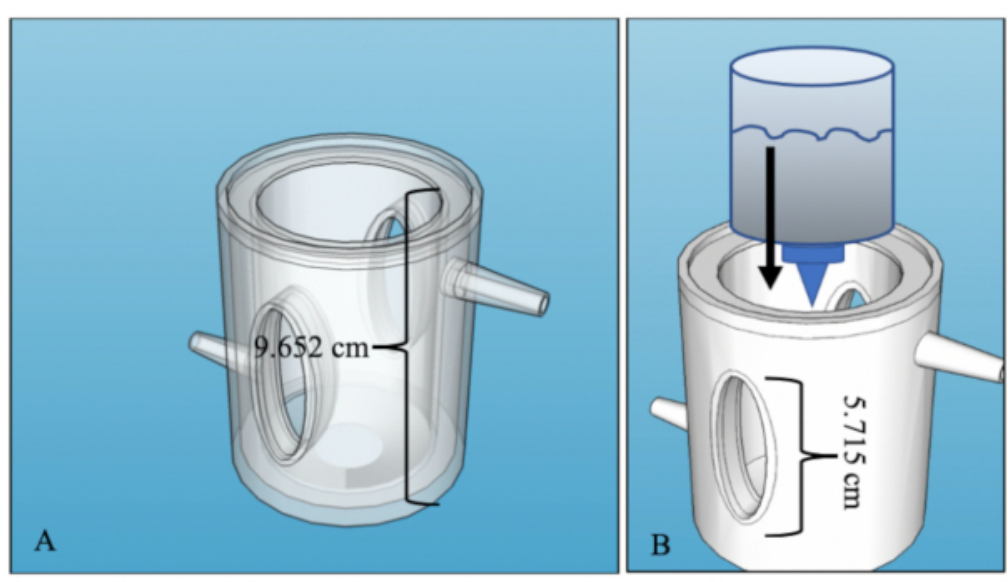

Figure 2: 3D printed condenser. (A) Schematic of a 3D printed condenser showing condenser dimensions. (B) Placement of a glass ocean vessel inside the condenser to cool the ocean simulant. Please click here to view a larger version of this figure. 

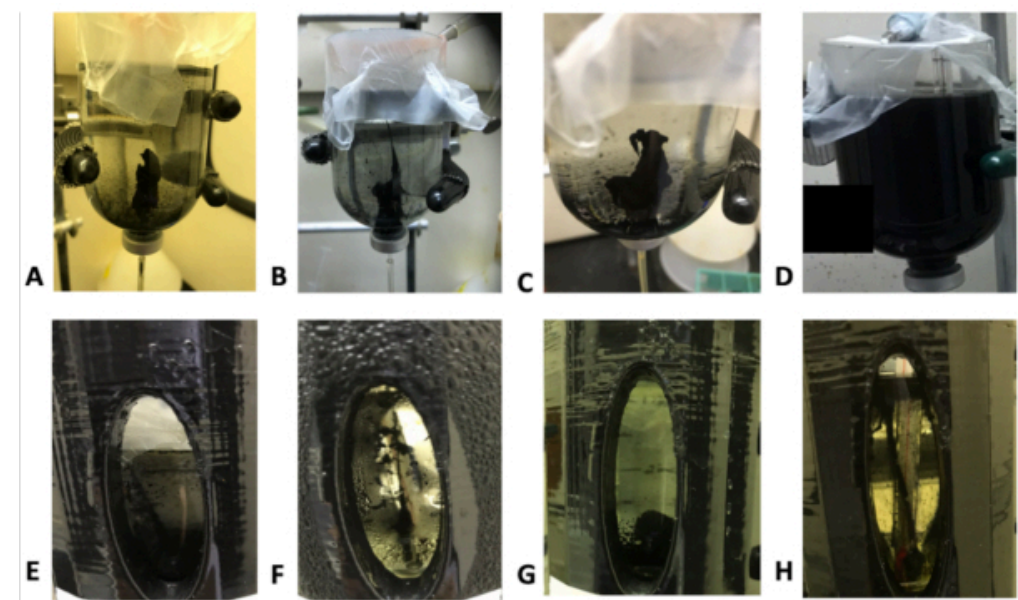

Figure 3: A variety of thermal and non-thermal gradient chimneys. (A-D) Non-thermal gradient control experiment from room-temperature hydrothermal fluid (HTF) to room-temperature ocean simulant. (A) $10 \mathrm{mM} \mathrm{Na} 2 \mathrm{~S} \cdot 9 \mathrm{H}_{2} \mathrm{O} \mathrm{HTF}$ and $20 \mathrm{mM}$ $\mathrm{FeCl}_{2} \cdot 4 \mathrm{H}_{2} \mathrm{O}$ ocean simulant. (B) $20 \mathrm{mM} \mathrm{Na} 2 \mathrm{~S} \cdot 9 \mathrm{H}_{2} \mathrm{O} \mathrm{HTF}$ and $10 \mathrm{mM} \mathrm{FeCl} 2 \cdot 4 \mathrm{H}_{2} \mathrm{O}$ ocean simulant. (C) $20 \mathrm{mM} \mathrm{Na} 2 \mathrm{~S} \cdot 9 \mathrm{H}_{2} \mathrm{O}$ HTF and $20 \mathrm{mM} \mathrm{FeCl}_{2} \cdot 4 \mathrm{H}_{2} \mathrm{O}$ ocean simulant. (D) $20 \mathrm{mM} \mathrm{Na} 2 \mathrm{~S} \cdot 9 \mathrm{H}_{2} \mathrm{O} \mathrm{HTF}$ and $20 \mathrm{mM} \mathrm{FeCl} 2 \cdot 4 \mathrm{H}_{2} \mathrm{O}$ ocean simulant. (E-H) Thermal gradient chimney experiment from room-temperature HTF simulant to a cold ocean reservoir $\left(\sim 5-10^{\circ} \mathrm{C}\right)$. (E) $20 \mathrm{mM}$ $\mathrm{Na}_{2} \mathrm{~S} \cdot 9 \mathrm{H}_{2} \mathrm{O} \mathrm{HTF}$ and $10 \mathrm{mM} \mathrm{FeCl} 2 \cdot 4 \mathrm{H}_{2} \mathrm{O}$ ocean simulant. (F) $10 \mathrm{mM} \mathrm{Na} 2 \mathrm{~S} \cdot 9 \mathrm{H}_{2} \mathrm{O} \mathrm{HTF}$ and $20 \mathrm{mM} \mathrm{FeCl} \cdot 4 \mathrm{H}_{2} \mathrm{O}$ ocean simulant. (G) $20 \mathrm{mM} \mathrm{Na} 2 \mathrm{~S} \cdot 9 \mathrm{H}_{2} \mathrm{O} \mathrm{HTF}$ and $10 \mathrm{mM} \mathrm{FeCl} \cdot 4 \mathrm{H}_{2} \mathrm{O}$ ocean simulant. (H) $10 \mathrm{mM} \mathrm{Na} 2 \mathrm{~S} \cdot 9 \mathrm{H}_{2} \mathrm{O} \mathrm{HTF}$ and $20 \mathrm{mM}$ $\mathrm{FeCl}_{2} \cdot 4 \mathrm{H}_{2} \mathrm{O}$ ocean simulant. Please click here to view a larger version of this figure. 


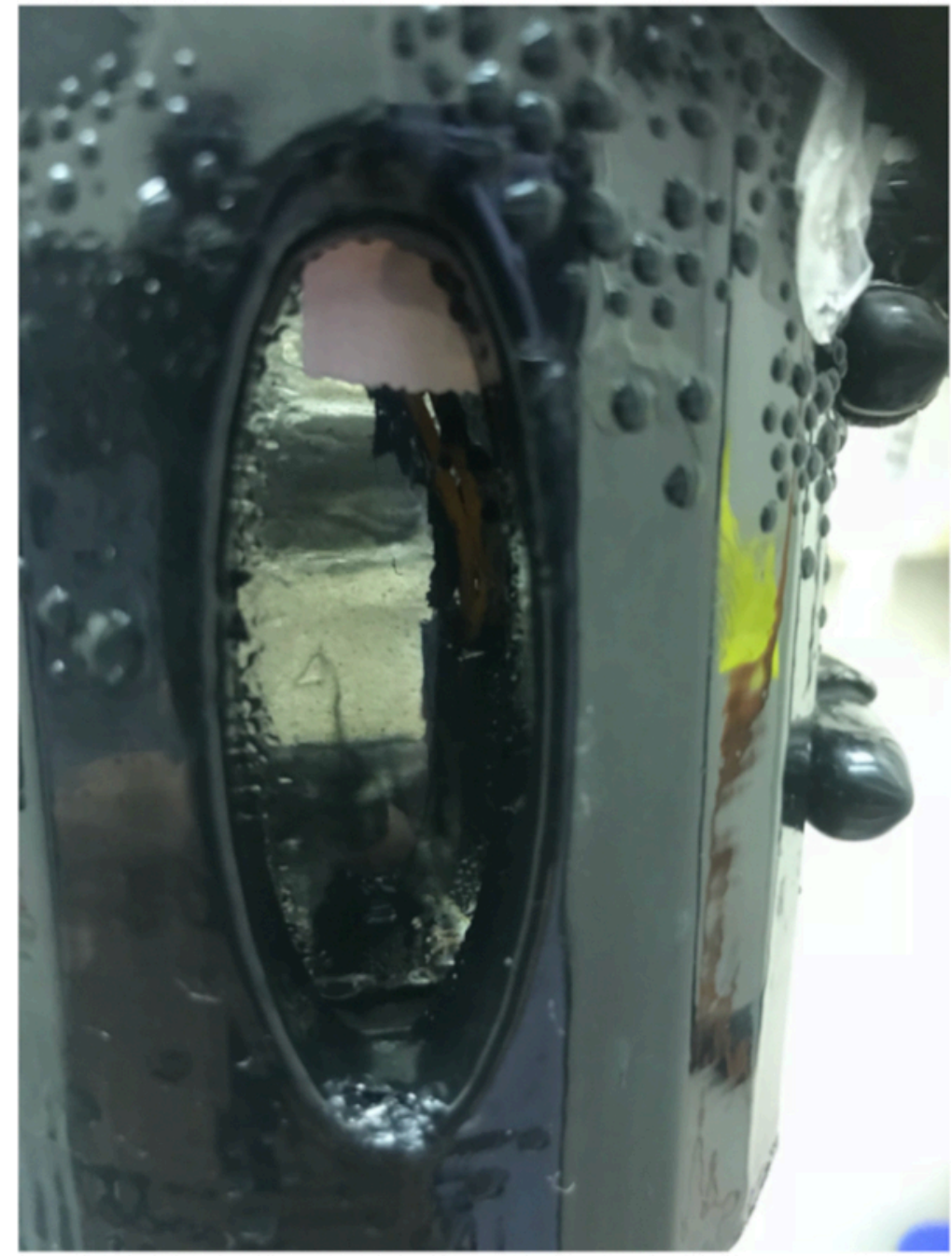

Figure 4: Thermal gradient experiment. Experiment performed with warm $\left(\sim 35-40{ }^{\circ} \mathrm{C}\right) 20 \mathrm{mM} \mathrm{Na} 2 \mathrm{~S} \cdot 9 \mathrm{H}_{2} \mathrm{O}$ solution injected into a cold $\left(\sim 5-10^{\circ} \mathrm{C}\right) 20 \mathrm{mM} \mathrm{FeCl} 2 \cdot 4 \mathrm{H}_{2} \mathrm{O}$ ocean simulant, producing small chimney strands. Please click here to view a larger version of this figure. 


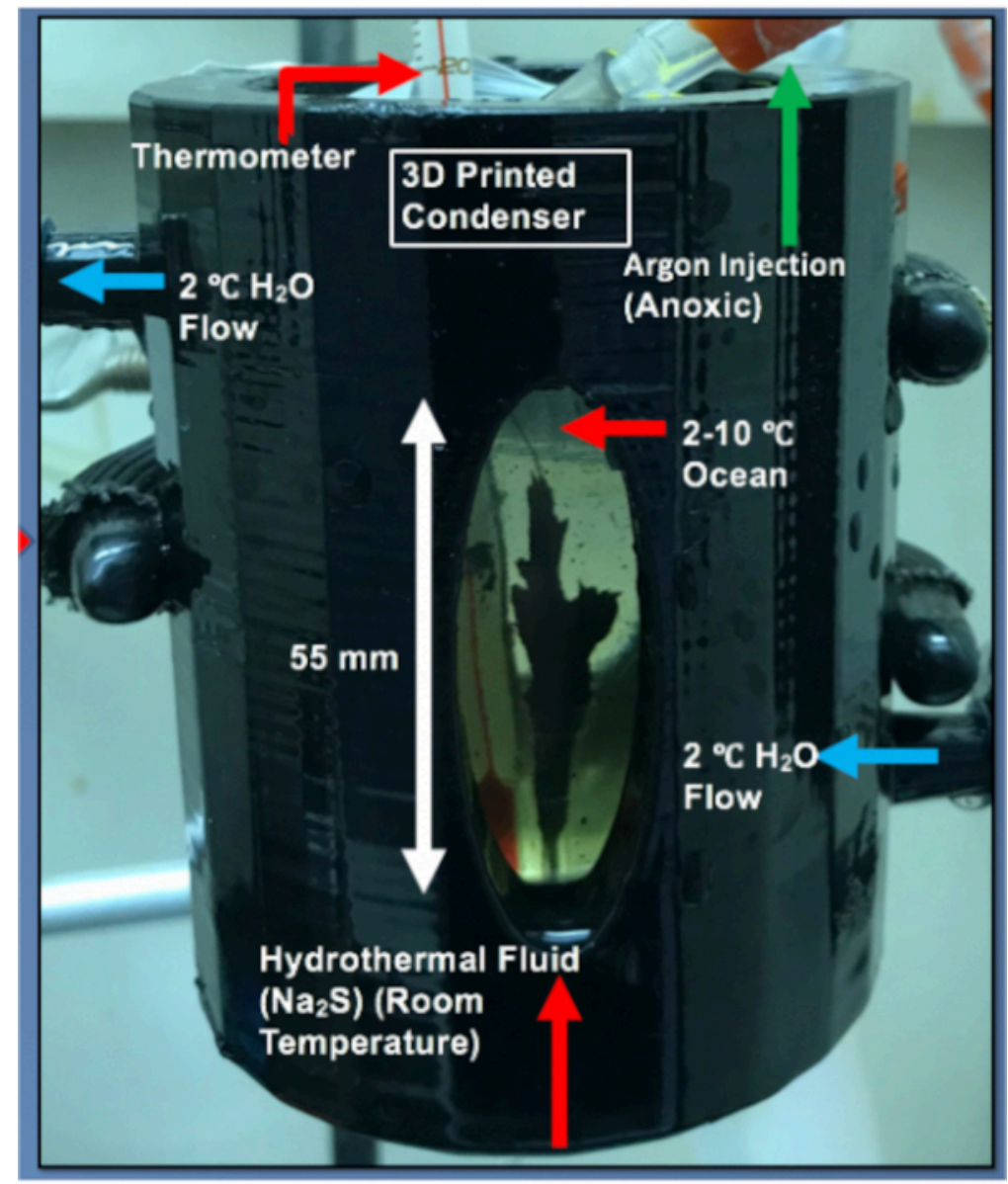

Figure 5: Effect of concentration of ocean simulant on chimneys. Higher concentrations $\left(\sim 50 \mathrm{mM} \mathrm{Na}_{2} \mathrm{~S} \cdot 9 \mathrm{H}_{2} \mathrm{O}, 10\right.$ $\mathrm{mM} \mathrm{FeCl}_{2} \cdot 4 \mathrm{H}_{2} \mathrm{O}$, and $200 \mathrm{mM} \mathrm{NaCl}$ ) of anoxic ocean simulants produced more structurally robust, taller chimneys. Roomtemperature sulfide solution was injected into $2-10^{\circ} \mathrm{C}$ ocean simulant. Please click here to view a larger version of this figure. 
$\mathbf{A}$

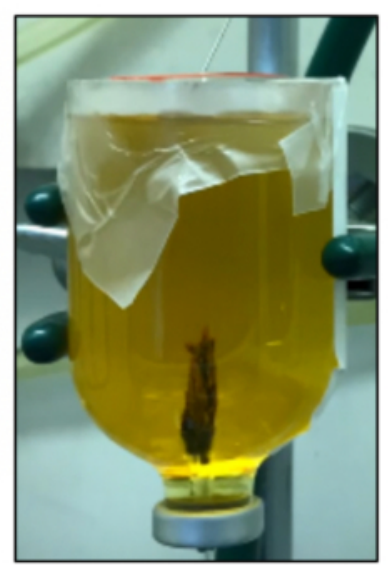

B

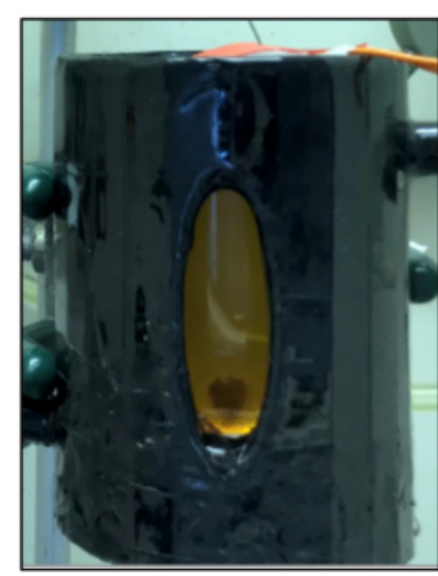

Figure 6: Simultaneous growth of thermal and non-thermal gradient chimneys. (A) $100 \mathrm{mM} \mathrm{FeCl} 2 \cdot 4 \mathrm{H}_{2} \mathrm{O}+100 \mathrm{mM}$ $\mathrm{FeCl}_{3} \cdot 6 \mathrm{H}_{2} \mathrm{O}$ ocean solution with a $200 \mathrm{mM} \mathrm{NaOH}$ hydrothermal fluid (HTF) fluid simulant at room temperature. (B) Thermal gradient experiment with the same concentrations with warm HTF at $\sim 35-50{ }^{\circ} \mathrm{C}$ into cold ocean simulant at $\sim 5-10{ }^{\circ} \mathrm{C}$. Please click here to view a larger version of this figure.

\begin{tabular}{|c|c|}
\hline Hydrothermal Fluid Chemistry (Injection) & Ocean Chemistry (Reservoir) \\
\hline $50 \mathrm{mM} \mathrm{Na} 2 \mathrm{~s}$ & $10 \mathrm{mM} \mathrm{FeCl}_{2} \cdot 4 \mathrm{H}_{2} \mathrm{O}+200 \mathrm{mM} \mathrm{NaCl}$ or $\mathrm{NaHCO}_{3}$ \\
\hline $20 \mathrm{mM} \mathrm{Na} 2 \mathrm{~S}$ & $10 \mathrm{mM} \mathrm{FeCl}_{2} \cdot 4 \mathrm{H}_{2} \mathrm{O}+200 \mathrm{mM} \mathrm{NaCl}$ or $\mathrm{NaHCO}_{3}$ \\
\hline $10 \mathrm{mM} \mathrm{Na} 2 \mathrm{~S}$ & $20 \mathrm{mM} \mathrm{FeCl}_{2} \cdot 4 \mathrm{H}_{2} \mathrm{O}+200 \mathrm{mM} \mathrm{NaCl}$ or $\mathrm{NaHCO}_{3}$ \\
\hline $200 \mathrm{mM} \mathrm{NaOH}$ & $100 \mathrm{mM} \mathrm{FeCl} 2 \cdot 4 \mathrm{H}_{2} \mathrm{O}+100 \mathrm{mM} \mathrm{FeCl}_{3} \cdot 6 \mathrm{H}_{2} \mathrm{O}$ \\
\hline
\end{tabular}

Table 1: Concentration matrix for both simulated ocean and hydrothermal fluid injection solutions.

\begin{tabular}{|c|c|c|}
\hline & \multicolumn{2}{|c|}{ Ocean Simulant Temperatures ${ }^{\circ} \mathbf{C}$} \\
\hline$\sim 23$ & $\sim 23$ & $5-10$ \\
\hline$\sim 35-50$ & $\sim 23$ & $5-10$ \\
\hline
\end{tabular}

Table 2: Thermal gradient experimental matrix. The hydrothermal fluid (HTF) temperature refers to the temperature of the fluid in the syringe; the actual temperature at the inlet to the ocean vial was between 20 and 35 degrees lower than the temperature within the syringe $\left(\sim 70^{\circ} \mathrm{C}\right)$ (see Supplementary Appendix 1, Figure 3, and Figure 4). 
Supplementary printable file. Please click here to download this file.

\section{Supplementary Appendix 1. Please click here to download} this file.

\section{Supplementary Appendix 2. Please click here to download} this file.

Supplementary Appendix 3. Please click here to download this file.

\section{Discussion}

\section{Effect of thermal gradients on simulated chimney growth:}

This experimental apparatus yielded several variations in chimney morphologies that were due to several experimental parameters. Chimneys of iron sulfide and iron hydroxide formed tall upright structures at room temperature, but formed more tenuous, stringy precipitates or flat mounds in the thermal gradient experiments. This was consistent with the findings of Herschy et al. where wispy, non-erect chimney precipitates were formed from a hydrothermal fluid heated to $70-80{ }^{\circ} \mathrm{C}$ and injected into room-temperature ocean simulant $^{33}$. There are various possible explanations for this: convective heat transfer can cause more natural buoyant forces (along with the forced pumping of the injection) to make the precipitate flow rapidly towards the top of the ocean vessel as it is forming. Alternatively, heating the syringe fluid makes the hydrothermal simulant less dense and thus more prone to rise vertically than to stabilize on top of the injection point. It is possible that this effect could be mitigated by changing the syringe injection rate to slower rates to allow the growth of a more stable structure. White et al. examined iron sulfide chimney growth with the hydrothermal simulant injected at extremely slow rates $(0.08 \mathrm{~mL} / \mathrm{h})$, and although the chimney took days to coalesce, it was structurally stable ${ }^{13}$. As Herschy et al. used peristaltic pumps at injection rates of $10-120 \mathrm{~mL} /$ $\mathrm{h}$, which is several orders of magnitude faster than the rates used in our thermal gradient experiments, it is not surprising that they also produced string-like chimney structures ${ }^{33}$.

Higher concentrations of precipitating reactants in the ocean and vent solutions can also yield more robust chimneys in thermal gradients. Higher chemical concentrations of precipitating ions (sulfide or hydroxide) in the hydrothermal fluid or ocean simulant can lead to higher overall precipitate mass, thus creating a stronger structure. As Herschy et al. and White et al. used lower concentrations of sulfide in the hydrothermal fluid $(10 \mathrm{mM})$, their structures were smaller than the ones produced in this work using higher (20-50 $\mathrm{mM}$ ) sulfide concentrations. Additionally, some studies of iron sulfide chimney growth have also included silica in the hydrothermal fluid along with the sodium sulfide, which can help produce more robust chimneys ${ }^{3,13,33}$. Silica chemical garden structures have also been used to simulate aspects of hydrothermal chimney growth ${ }^{34}$, and these tend to produce very robust structures that can be removed from the tube/ vial for physical analysis. However, the effects of temperature gradients on silica injection structures are not known and will be an area of further study.

\section{Considerations for future chimney simulation} experiments: The 3D printed condenser created in this study to cool the ocean vessel acted like a jacketed reaction vessel, but with some practical improvements: 1) the open top allowed sampling of the chimney and maintaining the anoxic ocean headspace; 2) the 3D printed part conferred easy reproducibility; 3 ) as the designs can be digitally edited, the apparatus can be quickly modified and re-printed if 
desired; and 4) the use of inexpensive materials made each condenser more cost-effective than the actual glassjacketed reaction vessels. These 3D printed condensers are a flexible and easily shared experimental apparatus that could be a useful way to standardize platforms for simulated hydrothermal chimney experiments across different research groups, allowing better comparison of samples and data. Files of the condenser can be sent to colleagues to print on their own for their educational or scientific purposes (see Supplemental 3D printing file of the condenser used in this work). This inexpensive setup could also be used as an undergraduate laboratory experiment for chemical gardens or chemobrionics $^{29,35}$.

In conclusion, this work describes a novel experimental apparatus using 3D printing to facilitate the growth of simulated hydrothermal chimneys in temperature gradient environments. The 3D printed condenser is able to cool the ocean simulant to near-freezing temperatures, similar to the seawater near seafloor hydrothermal systems. Meanwhile, a heated syringe was used to simulate the high-temperature hydrothermal fluid injecting into this cold ocean. The morphologies and structures of iron sulfide and iron hydroxide chimneys were affected by the thermal gradient: when both the ocean and the hydrothermal fluid simulants were at room temperature, the chimneys formed vertically oriented structures, but when the hydrothermal fluid was heated and the ocean was cooled, the formation of robust chimney structures was inhibited. For accurately simulating prebiotic reactions in such chimney systems with thermal gradients analogous to those of natural systems, it will be necessary to carefully control parameters such as injection rate and chemical composition of both vent and ocean simulants. The custom and inexpensive 3D printed condenser created for this study is similar in function to a jacketed reaction vessel and can be easily modified and distributed electronically to various research and educational groups for use in many types of chemobrionic experiments.

\section{Disclosures}

The authors have nothing to disclose.

\section{Acknowledgments}

This research was carried out at the Jet Propulsion Laboratory, California Institute of Technology, under a contract with NASA, supported by the NASA Astrobiology Institute Icy Worlds. Dr. Gabriel LeBlanc was supported in part by a Research Initiation Grant (2017-34) through the Oklahoma NASA EPSCoR Cooperative Agreement (NNX15AK42A). We would like to thank Heather Whitehead for assistance with the initial 3D printed condenser design, Kalind Carpenter for assistance with 3D printing, John-Paul Jones for helpful discussion on condenser vessels, Laura Rodriguez for help with temperature data analysis, and Erika Flores with laboratory assistance. Copyright 2020 California Institute of Technology.

\section{References}

1. Sojo, V., Herschy, B., Whicher, A., Camprubi, E., Lane, $\mathrm{N}$. The origin of life in alkaline hydrothermal vents. Astrobiolog.y. 16 (2), 181-197 (2016).

2. Barge, L. M. et al. From chemical gardens to fuel cells: Generation of electrical potential and current across self-assembling iron mineral membranes. Angewandte Chemie International Edition. 54 (28), 8184-8187 (2015).

3. Mielke, R. E. et al. Iron-sulfide-bearing chimneys as potential catalytic energy traps at life's emergence. Astrobiology. 11 (10), 933-950 (2011). 
4. Russell, M. J. et al. The drive to life on wet and icy worlds. Astrobiology. 14 (4), 308-343 (2014).

5. Russell, M. J., Hall, A. J. The emergence of life from iron monosulphide bubbles at a submarine hydrothermal redox and $\mathrm{pH}$ front. Journal of the Geological Society, London. 154 (3), 377-402 (1997).

6. Russell, M. J., Hall, A. J. The onset and early evolution of life. in Kesler, S.E., and Ohmoto, H., eds., Evolution of Early Earth's Atmosphere, Hydrosphere, and Biosphere —Constraints from Ore Deposits., Geological Society of America. 198, 1-32 (2006).

7. Hsu, H. W. et al. Ongoing hydrothermal activities within Enceladus. Nature. 519, 207-210 (2015).

8. Vance, S. et al. Hydrothermal systems in small ocean planets. Astrobiology.7 (6):987-1005 (2007).

9. Cardoso, S. S. S., Cartwright, J. H. E., Sainz-Díaz, C. I. Carbonate-hydroxide chemical-garden tubes in the soda ocean of Enceladus: abiotic membranes and microtubular forms of calcium carbonate. Icarus. 319, 337-348 (2019).

10. Russell, M. J., Murray, A. E., Hand, K. P. The possible emergence of life and differentiation of a shallow on irradiated icy worlds: the example of Europa. Astrobiology. 17, 1265-1273 (2017).

11. Yamaguchi, A. et al. Electrochemical $\mathrm{CO} 2$ reduction by Ni-containing iron sulfides: How is $\mathrm{CO} 2$ electrochemically reduced at bisulfide-bearing deep-sea hydrothermal precipitates?. Electrochimica Acta. 141, 311-318 (2014).

12. Roldan, A., et al. Bio-inspired $\mathrm{CO} 2$ conversion by iron sulfide catalysts under sustainable conditions. Chemical Communications. 51 (35):7501-7504 (2015).
13. White, L. M., Bhartia, R., Stucky, G. D., Kanik, I., Russell, M. J. Mackinawite and greigite in ancient alkaline hydrothermal chimneys: identifying potential key catalysts for emergent life. Earth and Planetary Science Letters. 430, 105-114 (2015).

14. Barge, L. M., Flores, E., Baum, M. M, VanderVelde, D. G., Russell, M. J. Redox and pH gradients drive amino acid synthesis in iron oxyhydroxide mineral systems. Proceedings of the National Academy of Sciences. 116 (11):4828-4833 (2019).

15. Macleod, G., McKeown, C., Hall, A. J., Russell, M. J. Hydrothermal and oceanic $\mathrm{pH}$ conditions of possible relevance to the origin of life. Origins of Life and Evolution of the Biosphere. 24 (1), 19-41 (1994).

16. McGlynn, S. E., Kanik, I., Russell, M. J. Peptide and RNA contributions to iron-sulphur chemical gardens as life's first inorganic compartments, catalysts, capacitors and condensers. Philosophical Transactions of the Royal Society A: Mathematical, Physical and Engineering Sciences. 370 (1969), 3007-3022 (2012).

17. Cutler, K. B. et al. Rapid sea-level fall and deep-ocean temperature change since the last interglacial period. Earth and Planetary Science Letters. 206 (3-4), 253-271 (2003).

18. Kelley, D. S. et al., An off-axis hydrothermal vent field near the Mid-Atlantic Ridge at 30 N. Nature. 412 (6843), 145-149 (2001).

19. Kelley, D. S. et al. A serpentinite-hosted ecosystem: the Lost City hydrothermal field. Science. 307 (5714), 1428-1434 (2005). 
20. Price, R. et al. Alkaline vents and steep $\mathrm{Na}+$ gradients from ridge-flank basalts-Implications for the origin and evolution of life. Geology. 45 (12), 1135-1138 (2017).

21. Proskurowski, G. et al. Abiogenic hydrocarbon production at Lost City hydrothermal field. Science. 319 (5863), 604-607 (2008).

22. Francheteau, J. et al. Massive deep-sea sulphide ore deposits discovered on the East Pacific Rise. Nature. 277 (5697), 523-528 (1979).

23. Spiess, F. N. et al. East Pacific Rise: hot springs and geophysical experiments. Science. 207 (4438), 1421-1433 (1980).

24. Hekinian, R., Fevrier, M., Bischoff, J. L., Picot, P., Shanks, W. C. Sulfide deposits from the East Pacific Rise near 21 N. Science. 207 (4438), 1433-1444 (1980).

25. Haymon, R. M. Growth history of hydrothermal black smoker chimneys. Nature. 301 (5902), 695-698 (1983).

26. Ishii, T., Kawaichi, S., Nakagawa, H., Hashimoto, K., Nakamura, R. From chemolithoautotrophs to electrolithoautotrophs: $\mathrm{CO}_{2}$ fixation by $\mathrm{Fe}$ (II)-oxidizing bacteria coupled with direct uptake of electrons from solid electron sources. Frontiers in Microbiology. 6, 994 (2015).

27. Barge, L. M. et al. Pyrophosphate synthesis in iron mineral films and membranes simulating prebiotic submarine hydrothermal precipitates. Geochimica et Cosmochimica Acta. 128, 1-2 (2014).

28. Barge, L. M., White, L. M. Experimentally testing hydrothermal vent origin of life on Enceladus and other icy/ocean worlds. Astrobiology. 17 (9), 820-833 (2017).
29. Barge, L. M. et al. Chemical gardens as flow-through reactors simulating natural hydrothermal systems. Journal of Visualized Experiments. 105, e53015 (2015).

30. Morse, J. W., Mackenzie, F. T. Hadean ocean carbonate geochemistry. Aquatic Geochemistry. 4 (3-4), 301-319 (1998).

31. Russell, M. J., Arndt N. T. Geodynamic and metabolic cycles in the Hadean. Biogeosciences. 2 (1), 97-111 (2005).

32. Price, R. E., Giovannelli, D. A Review of the geochemistry and microbiology of marine shallow-water hydrothermal vents in Reference Module in Earth Systems and Environmental Science., Elsevier, New York, USA (2017).

33. Herschy, B. et al. An origin-of-life reactor to simulate alkaline hydrothermal vents. Journal of Molecular Evolution. 79 (5-6), 213-227 (2014).

34. Barge, L. M. et al. Characterization of iron-phosphatesilicate chemical garden structures. Langmuir. 28 (8), 3714-3721 (2012).

35. Barge, L. M. et al. From chemical gardens to chemobrionics. Chemical Reviews. 115 (16), 8652-8703 (2015). 